\title{
Publisher's Note: Focal Molography: Coherent Microscopic Detection of Biomolecular Interaction [Phys. Rev. X 4, 031024 (2014)]
}

Christof Fattinger

(Received 17 October 2014; published 29 October 2014)

DOI: 10.1103/PhysRevX.4.049901

Subject Areas: Biological Physics, Interdisciplinary Physics

This paper was published online on 11 August 2014 with a typographical error in Eq. (1). The second line of Eq. (1) should read as

$$
=\frac{9 \pi^{2} n_{0}^{4}}{r^{2} \lambda^{4}}\left(\frac{d n}{d c}\right)^{2} \frac{M_{R}^{2}}{N_{A}^{2}} \bar{n}(\rho R)
$$

The equation has been corrected online as of 17 October 2014.

Published by the American Physical Society under the terms of the Creative Commons Attribution 3.0 License. Further distribution of this work must maintain attribution to the author(s) and the published articles title, journal citation, and DOI. 